Año 9, Núm. 24 (Edición Especial-diciembre 2016)

http://revistainvestigacionacademicasinfrontera.com
Revista de Investigación

Académica sin Frontera ISSN: 2007-8870

\title{
Igualdad, Género y Políticas Públicas
}

\author{
Ponentes: \\ Dr. Félix Mauro Higuera Sánchez \\ fhiquera@navojoa.uson.mx \\ (045) 6424280681 \\ Dra. Celia Guadalupe Torres Ayala \\ cgtorres@navojoa.uson.mx \\ (045) 6428535394 \\ Claudian Yanira Carrillo Valenzuela
}

\section{Resumen}

La globalización ha impulsado la conformación de replantear las políticas de igualdad de género en América Latina, lo que ha motivado el confrontar una serie de problemáticas respecto a la aceptación de su perspectiva en las políticas públicas de las naciones; destacando los logros del impulso de agrupaciones de mujeres, a través de organismos internacionales, los diversos gobiernos adoptando de forma institucional diversas acciones y programas orientados a lograr una igualdad de género, no solo a nivel Internacional sino también a nivel nacional, teniendo una incidencia importante tanto en el ámbito legislativo, ejecutivo y el judicial donde se han visto grandes cambios. Se plantea en el trabajo de investigación el realizar una descripción y análisis de las políticas de igualdad y de género en la legislación de acuerdo a los tratados internacionales, que han dado forma a la concepción actual. Usando como metodología: un estudio de tipo 


\section{http://revistainvestigacionacademicasinfrontera.com}

Revista de Investigación

Académica sin Frontera ISSN: 2007-8870

descriptivo y analítico, de investigación documental con fuentes doctrinarias: normativas y jurisprudenciales. Como conclusiones: de lo cual el desarrollo de la igualdad de género en nuestro país se requiere un cambio de cultura, y conocimientos de la sociedad inmersa en estos cambios.

\section{Introducción}

A través de tiempo se ha dado el reconocimiento de la igualdad de género, esta lucha se inició hace aproximadamente 250 años, ya que se consideraban que las mujeres eran naturalmente diferentes e inferiores a los hombres, diversas naciones iniciaron el reconocimiento de la igualad entre los hombre y las mujeres, pero fue hasta inicios del siglo pasado XX donde se le da el reconocimiento a las mujeres que debían tener un mismo estatus jurídico suficiente para participar en actos públicos de la época, así como para participar tanto en los cargos de elección popular como también en el trabajo y su participación importante dentro de la economía que con anterioridad no se le había dado su debido valor.

Un vértice relevante a estos derechos se da en el reconocimiento en el año de 1979 de la de la Convención para la Eliminación de todas las formas de discriminación (CEDAW, por sus siglas en inglés) donde se aceptan planamente por parte de los estados internacionales el garantizar a las mujeres en materia civil, política, económica y social. Mismo documento que fue aceptado y ratificado por Los Estados Unidos Mexicanos en 198, comprometiéndose en combatir las desigualdades que existían en esa actualidad entre los hombres y mujeres, ahora bien, no solo basta una acción gubernamental de estado sino una cultura general para erradicar esta problemática social

Por lo que es necesario el ver el alcance de estos logros y como ha permeado en los diferentes sectores de la sociedad principalmente en la políticas públicas, ya 


\section{http://revistainvestigacionacademicasinfrontera.com}

Revista de Investigación

Académica sin Frontera ISSN: 2007-8870

que este concepto lo debemos entender como el encadenamiento de actividades y medidas tendientes a la atención de la equidad y el género dentro del sistema político administrativo de nuestra nación, con el objetivo de resolver el problema planteado

\section{Planteamiento del tema.}

En esta ponencia se abordara primeramente el análisis de algunos conceptos manejados por tratadistas nacionales e internaciones y sus diversos tratados, sobre la igualdad, el género y lo que se ha avanzado en políticas públicas en nuestro país.

Las políticas públicas son el conjunto de objetivos, decisiones y acciones que lleva a cabo un gobierno para solucionar los problemas que en un momento determinado los ciudadanos y el propio gobierno consideran prioritarios.

Desde este punto de vista, las políticas públicas se pueden entender como un proceso que se inicia cuando un gobierno o un directivo público detecta la existencia de un problema que, por su importancia, merece su atención y termina con la evaluación de los resultados que han tenido las acciones emprendidas para eliminar, mitigar o variar ese problema. (Tamayo Sáenz, (1997)

La Asamblea General de las Naciones Unidas, (2016) destaca que uno de los antecedentes más importantes sobre la igualdad y el género es la Comisión de la Condición Jurídica y Social de la Mujer se reunió por primera vez en Lake Success, Nueva York, en febrero de 1947, poco después de la creación de las Naciones Unidas. En aquel momento, los 15 representantes gubernamentales que formaban la Comisión eran mujeres. Desde su nacimiento, la Comisión contó con el apoyo de una dependencia de las Naciones Unidas que más tarde se convertiría en la División para el Adelanto de la Mujer, dependiente de la 


\section{http://revistainvestigacionacademicasinfrontera.com}

Revista de Investigación

Académica sin Frontera ISSN: 2007-8870

Secretaría de las Naciones Unidas. La Comisión de la Condición Jurídica y Social de la Mujer forjó una estrecha relación con las organizaciones no gubernamentales; aquellas reconocidas como entidades consultivas por el Consejo Económico y Social eran invitadas a participar en las sesiones de la Comisión en calidad de observadoras.

En años posteriores realizaron una gran intervención en la Declaración Universal de Derechos Humanos, lo cual se obtuvo un gran logro de integrar el concepto de humanidad logrando un lenguaje nuevo y más inclusivo.

La comisión antes mencionada colaboro en diversas reuniones y convenciones sobre los derechos de la mujer como la Convención sobre los Derechos Políticos de la Mujer de 1953, el cual se considera el primer antecedente internacional que protegen los derechos políticos de las mujeres, también apoyo la lucha de los derechos, en el matrimonio, el trabajo bien remunerado hacia la mujer es decir el pago igual de salario entre el hombre y la mujer así como la reducción de la discriminación hacia este grupo de personas vulnerables.

\section{Referencias teóricas}

Hay que destacar Naciones Unidas para los Derechos Humanos,(2016)el pacto internacional de derechos económicos, sociales y culturales donde Adopción: Nueva York, EUA, 16 de diciembre de 1966, se Adhesión de México: 23 de marzo de 1981, decreto promulgado en el diario oficial del 12 de mayo de 1981, donde se destacan los siguientes artículos:

Artículo I

1. Todos los pueblos tienen el derecho de libre determinación. En virtud de este derecho establecen libremente su condición política y proveen, asimismo, a su desarrollo económico, social y cultural. 


\section{(Edición Especial-diciembre 2016)}

\section{http://revistainvestigacionacademicasinfrontera.com}

Revista de Investigación

Académica sin Frontera ISSN: 2007-8870

2. Para el logro de sus fines, todos los pueblos pueden disponer libremente de sus riquezas y recursos naturales, sin perjuicio de las obligaciones que derivan de la cooperación económica internacional basada en el principio de beneficio recíproco, así como del derecho internacional. En ningún caso podría privarse a un pueblo de sus propios medios de subsistencia.

3. Los Estados Partes en el presente Pacto incluso los que tienen la responsabilidad de administrar territorios no autónomos y territorios en fideicomiso, promoverán el ejercicio del derecho de libre determinación, y respetarán este derecho de conformidad con las disposiciones de la Carta de las Naciones Unidas.

\section{Artículo 2}

Cada uno de los Estados Partes en el presente Pacto se compromete a adoptar medidas, tanto por separado como mediante la asistencia y la cooperación internacionales, especialmente económicas y técnicas, hasta el máximo de los recursos de que disponga, para lograr progresivamente, por todos los medios apropiados, inclusive en particular la adopción de medidas legislativas, la plena efectividad de los derechos aquí reconocidos.

2. Los Estados Partes en el presente pacto se comprometen a garantizar el ejercicio de los derechos que en él se enuncian sin discriminación alguna por motivos de raza, color, sexo, idioma, religión opinión política o de otra índole, origen nacional o social, posición económica nacimiento o cualquier otra condición social. 


\section{http://revistainvestigacionacademicasinfrontera.com}

Revista de Investigación

Académica sin Frontera ISSN: 2007-8870

3. Los países en vías de desarrollo, teniendo debidamente en cuenta los derechos humanos y su economía nacional, podrán determinar en qué medida garantizarán los derechos económicos reconocidos en el presente pacto a personas que no sean nacionales suyos.

El Pacto internacional de los derechos económicos, sociales y culturales, han significado otro avance en materia de igualdad y no discriminación. En cuanto a los derechos civiles y políticos son diversos los artículos que procuran la igualdad entre mujeres y hombres.

Destacando que se incluye el término individuos por lo que también se da un logro de igualdad de derechos donde se manifiesta que todo ser humano tiene derecho, en todas partes, al reconocimiento de su personalidad jurídica y que toda persona tiene derecho a la libertad de pensamiento, de conciencia y de religión.

Se habla también de entorno familiar donde habla de matrimonio y se protege a la niñez, donde ningún menor podrá ser discriminado por ningún motivo, ya sea por diferentes condiciones entre ellos el sexo.

Concepto de Igualdad

Según Saldaña Perez, (2007) Es un concepto que compromete profundamente la visión política del Estado, pues la igualdad jamás se encuentra desvinculada de la libertad y el derecho, términos de suyos tan cuestionados que conducen a confusión. y citando Saldaña a Dworkin, un concepto de igualdad no es equivalente con las concepciones de la igualdad, ya que un concepto debe referirse a un conjunto de ideas presentes en toda interpretación de una realidad determinada, bajo fórmulas cargadas de intencionalidad y significado que aluden a un estándar valorativo, específico y abstracto, cuyos destinatarios son los 


\section{(Edición Especial-diciembre 2016)}

\section{http://revistainvestigacionacademicasinfrontera.com}

Revista de Investigación

Académica sin Frontera

ISSN: 2007-8870

llamados a aplicar., así mismo Carbonell, (2010) retomando las ideas de Dworkin ha distinguido la "igualdad económica" de la "igualdad política", señalando que la primera recoge los intereses del bienestar, haciendo de los recursos un elemento instrumental.

La igualdad económica, de acuerdo con el mismo autor, se puede definir de dos modos distintos. El primero es tomando en cuenta los recursos con que cuentan los individuos, de tal forma que la igualdad económica vendría determinada en términos de riqueza o de ingreso. El segundo modo de definir la igualdad económica no tiene que ver con la igualdad de ingresos o de riqueza, sino con el bienestar de las personas, determinada por la cantidad de recursos de que dispone el individuo para la realización de sus fines

De lo cual también se puntualiza el auto citado Carbonell, (2010) El concepto de igualdad, desde el punto de vista normativo, es un concepto indeterminado, que requiere de un esfuerzo creativo importante por parte del intérprete al momento de juzgar si una determinada norma o situación pueden lesionarlo. Tiene razón Francisco Rubio Llorente cuando afirma que "la igualdad designa un concepto relacional, no una cualidad de una persona, de un objeto (material o ideal), o de una situación, cuya existencia pueda ser afirmada o negada como descripción de esa realidad aisladamente considerada; es siempre una relación que se da al menos entre dos personas, objetos o situaciones. Es siempre el resultado de un juicio que recae sobre una pluralidad de elementos (en el caso límite, al menos una dualidad), los 'términos de la comparación', entre los cuales debe existir al mismo tiempo alguna diversidad, aunque sólo sea espacial y/o temporal, pues de otro modo, como es obvio, no cabría hablar de pluralidad. La diferencia, al menos numérica, entre los elementos comparados es condición de posibilidad del juicio de igualdad". 


\section{http://revistainvestigacionacademicasinfrontera.com}

Revista de Investigación

Académica sin Frontera ISSN: 2007-8870

Conceptos y Principios Fundamentales

De acuerdo con la Cámara de Diputados , (2016) los principios que guían a la Comisión de Equidad y Género nos definen "Equidad. Principio de acción dirigido hacia el logro de condiciones justas en el acceso y control de los bienes culturales y materiales tanto para las mujeres como para los hombres. Al ser un término vinculado con la justicia, obliga a plantear los objetivos que deben conseguirse para avanzar hacia una sociedad más justa";

El Tribunal Federal de Conciliación y Arbitraje, (2016) El término equidad alude a una cuestión de justicia: es la distribución justa de los recursos y del poder social en la sociedad; se refiere a la justicia en el tratamiento de hombres y mujeres, según sus necesidades respectivas. En el ámbito laboral el objetivo de equidad de género suele incorporar medidas diseñadas para compensar las desventajas de las mujeres.

La equidad de género permite brindar a las mujeres y a los hombres las mismas oportunidades, condiciones, y formas de trato, sin dejar a un lado las particularidades de cada uno(a) de ellos (as) que permitan y garanticen el acceso a los derechos que tienen como ciudadanos(as).

A lo cual manejan también el Termino Género. Como el Conjunto de características sociales, culturales, políticas, psicológicas, jurídicas y económicas, asignadas según el momento histórico, a las personas en forma diferenciada de acuerdo al sexo. El género se construye a partir de la diferencia anatómica del orden sexual, no es sinónimo de mujer; hace referencia a lo socialmente construido. Refiere diferencias y desigualdades entre mujeres y hombres, por razones sociales y culturales que se manifiestan por los roles sociales (reproductivo, productivo y de gestión comunitaria), así como las 


\section{(Edición Especial-diciembre 2016)}

\section{http://revistainvestigacionacademicasinfrontera.com}

Revista de Investigación

Académica sin Frontera

ISSN: 2007-8870

responsabilidades, el conocimiento 0 la prioridad en el uso, control, aprovechamiento y beneficio de los recursos;

El Tribunal Federal de Conciliación y Arbitraje, (2016) Nos define como Género es una traducción del vocablo inglés gender. Parte de las supuestas diferencias biológicas entre los sexos, así como las desigualdades entre los roles que se asignan a hombres y mujeres en función del contexto socioeconómico, histórico, político, cultural y religioso de las diferentes sociedades en las que viven esos hombres y mujeres.

Y la Igualdad. Como principio Implica que todas las personas, sin excepción, son iguales ante la ley y ante el Estado, por lo que deben tener las mismas oportunidades de satisfacción de sus necesidades y de ejercicio de los derechos;

\section{Políticas Públicas}

Diferentes naciones en los últimos años han realizado modificaciones esenciales en sus políticas para combatir la problemática de la igualdad y el género las naciones deben aplicar y conformar políticas públicas encaminadas a resolver esta problemática como por ejemplo Brasil, Colombia, costa rica Uruguay, y México entre otros.

Como lo manifiestan Bernavente R \& Valdés B, (2014) un ejemplo a seguir son las políticas que se analizan del Brasil y del Uruguay son políticas orientadas a enfrentar la violencia dirigida a las mujeres por ser mujeres. Son políticas que expresan cómo las sociedades y los Estados han avanzado en la "politización de lo privado", convirtiendo en objeto de política pública problemas que han sido tradicionalmente considerados privados. Estas políticas tienden a la justicia de género, por una parte, en la medida en que promueven el logro de la autonomía física de las mujeres y, por otra, sobre todo, porque al combatir una práctica 


\section{(Edición Especial-diciembre 2016)}

\section{http://revistainvestigacionacademicasinfrontera.com}

Revista de Investigación

Académica sin Frontera

ISSN: 2007-8870

basada en la desigualdad y la discriminación de género ponen en cuestión el orden sobre el que se basa la violencia contra las mujeres.

Las Políticas Públicas se pueden entender como el ámbito privilegiado de realización del "pacto" entre Estado y sociedad. Un nuevo papel del Estado, en el sentido de hacerlo más ágil y organizador. Aquí podemos rescatar el sentido participación entre estos dos actores, pero el objetivo final de beneficio a la sociedad es como lo veremos más adelante un punto que muchas veces queda olvidado, de aquí el fracaso de muchas Políticas Públicas.

Los maestros Ruiz Lopez \& Cadenas Ayala, (2016) nos manifiestan Las Políticas Públicas son "el conjunto de actividades de las instituciones de gobierno, actuando directamente o a través de agentes, y que van dirigidas a tener una influencia determinada sobre la vida de los ciudadanos". Pallares señala: las Políticas Públicas deben ser consideradas como un "procesos decisional", un conjunto de decisiones que se llevan a cabo a lo largo de un plazo de tiempo. Pallares, al mencionar esa persuasión sobre la población no comenta si es de índole positiva o negativa, pero podemos decir que en ocasiones el bienestar se ve cuestionado en una política restrictiva o de imposición fiscal por ejemplo, logrando ciertamente esa modificación conductual. Aunque la mayoría de las Políticas Públicas tienen un impacto directo en el bienestar de la población.

Por lo que se debe considerar que las políticas públicas son actividades realizadas por el gobierno dentro de su potestad con un interés público, en base a determinaciones y la posibilidad de su cumplimiento, donde se sustenta el beneficio público, y la resolución ideal para afrontar esa problemática

De lo cual para la realización de políticas públicas se tiene que tomar en cuanta una diversidad de actores dentro de la sociedad donde cuentan con una conexión con el fin a lograr. 


\section{http://revistainvestigacionacademicasinfrontera.com}

Revista de Investigación

Académica sin Frontera ISSN: 2007-8870

Debiendo tener en cuenta que su surgimiento es en base a las negociaciones políticas de las partes intervinientes, y que su aplicación y funcionamiento es de acuerdo a las particularidades de cada estado.

En el caso de México en su plan de desarrollo Plan Nacional de Desarrollo 20132018, impulsa En lo relevante de nuestra carta magna La Constitución Política de los Estados Unidos Mexicanos, nos da pauta apara la aplicación de políticas públicas en su plan de desarrollo, realizando propuestas y líneas de acción a seguir para llevar a México a máximo potencial. Ya que debemos considerar que nuestro desarrollo va unido al contexto particular de los diversos pises con que tiene relación México por lo que se debe apreciar tanto el contexto internacional como la economía interna de nuestro país para que en esa medida sean aplicables los cambios necesarios para nuestro progreso.

\section{Metodología}

La presente investigación se realizó un análisis bibliográfico sobre la temática abordada realizando una elección de la misma debida a la gran variedad de puntos de vista de los autores y bibliografía eligiéndose la que se considero la más apropiada y relevante del tema investigado de la igualdad, genero y políticas públicas.

\section{Resultado y conclusiones}

De lo que podemos destacar de los antes investigado es que en importante precisar se tienen varios retos a vencer como el revisar si todos los cambios que se han realizado en base a plan nacional de desarrollo, los programas institucionales y administrativos, en los tres niveles de gobierno que tiendan a contribuir la disminución de una desigualdad, como en el problema del género y 
http://revistainvestigacionacademicasinfrontera.com

principalmente si se han cumplido con las propuestas planteadas inicialmente, y si es necesario una trasformación de los mismos.

Se necesita mayor vigilancia en gasto público que efectivamente se destinen los recursos a combatir y erradicar la desigualdad en todos los sentidos, políticos, económicos laborales, de justicia que han existido avances pero no en la medida deseada. Así como una educación de calidad para fortalecer el capital humano para que este capital esté en condiciones de enfrentar un mundo cada día más competitivamente globalizado.

Una garantía efectiva de nuestra democracia, lo que dará certeza y seguridad a la sociedad además de un ejercicio efectivo de los derechos sociales, a una salud garantizada.

Es necesario el tener un seguimiento claro con resultados y responsabilidades que nos muestren como se va marcando nuestro desarrollo y principalmente frente a las economías de las demás naciones, que los resultados den muestras de una igualdad efectiva de una cultura de la paz y la justicia lo que nos traduciría en una trasformación integral de México, ya que la sociedad debe mostrar sus deseos de cambio y de renovación social.

\section{Fuentes consultadas}

Cámara de Diputados . (10 de octubre de 2016). Honorable Cámara de Diputados. Obtenido de Honorable Cámara de Diputados: http://www3.diputados.gob.mx/camara/001_diputados/008_comisiones/x/00 1_ordinarias/015_equidad_y_genero/001_equidad_y_genero

Tamayo Sáenz, M. (1997). La nueva nueva administración pública. En M. Tamayo Sáenz, La nueva nueva administración pública (pág. 2). Madrid: Alianza Universidad. 
Asamblea General de las Naciones Unidas. (07 de Octubre de 2016). ONU Mujeres. Obtenido de ONU Mujeres: http://www.unwomen.org/es/csw/briefhistory

Bernavente R, M. C., \& Valdés B, A. (2014). Políticas públicas para la igualdad de género, un aporte a la autonomía de la mujeres. En M. C. Bernavente R, \& A. Valdés B, Políticas públicas para la igualdad de género, un aporte a la autonomía de la mujeres (pág. 23). Santiago de Chile: Naciones Unidas.

Carbonell, M. (30 de Junio de 2010). Direitos Fundamentais e justica. Obtenido de Direitos Fundamentais e justica: http://www.dfj.inf.br/Arquivos/PDF_Livre/11_Dout_Estrangeira_3.pdf

El Tribunal Federal de Conciliación y Arbitraje. (10 de Octubre de 2016). Micrositio de la Comisión de lgualdad de Género. Obtenido de Micrositio de la Comisión de Igualdad de Género: http://www.tfca.gob.mx/es/TFCA/cbEG

Naciones Unidas para los Derechos Humanos. (11 de Octubre de 2016). Naciones Unidas para los Derechos Humanos. Obtenido de Naciones Unidas para los Derechos Humanos: http://www.ohchr.org/SP/Professionallnterest/Pages/CCPR.aspx

Ruiz Lopez, D., \& Cadenas Ayala, C. E. (11 de octubre de 2016). IUS Revista Júridica. Obtenido de IUS Revista Júridica: http://www.unla.mx/iusunla18/reflexion/QUE\%20ES\%20UNA\%20POLITICA \%20PUBLICA\%20web.htm

Saldaña Perez, L. (2007). Poder Género y derecho, igualdad entre hombres y mujeres en México. En L. Saldaña Perez, Poder Género y derecho, igualdad entre hombres y mujeres en México (pág. 17). México: Comisión Nacional de Derechos Humanos. 